\title{
Cytotoxic T cell vaccination with PLGA microspheres interferes with influenza A virus replication in the lung and suppresses the infectious disease
}

\author{
Valerie L. Herrmann ${ }^{\mathrm{a}}$, Carmen Hartmayer ${ }^{\mathrm{b}}$, Oliver Planz ${ }^{\mathrm{b}, *}$, Marcus Groettrup ${ }^{\mathrm{a}, \mathrm{c}, * *}$ \\ a Division of Immunology, Department of Biology, University of Konstanz, 78457 Konstanz, Germany \\ ${ }^{\mathrm{b}}$ Department of Immunology, Interfaculty Institute for Cell Biology, Eberhard Karls University Tuebingen, 72076 Tuebingen, Germany \\ c Biotechnology Institute Thurgau (BITg) at the University of Konstanz, 8280 Kreuzlingen, Switzerland
}

Keywords:

Cytotoxic T lymphocytes

Influenza A virus

Lung

Mucosal immunity

PLGA microspheres

Vaccination

\begin{abstract}
A B S T R A C T
Current influenza virus vaccines aim to elicit antibodies directed toward viral surface glycoproteins, which however are prone to antigenic drift. Cytotoxic T lymphocytes (CTLS) can exhibit heterosubtypic immunity against most influenza A viruses. In our study, we encapsulated the highly conserved, immunodominant, HLA A*0201 restricted epitope from the influenza virus matrix protein $M 1_{58}{ }_{66}$ together with TLR ligands in biodegradable poly(D,L lactide co glycolide) (PLGA) microspheres. Subcutaneous immunization of transgenic mice expressing chimeric HLA $A^{*} 0201$ molecules with these microspheres induced a strong and sustained CTL response which sufficed to prevent replication of a recombinant vaccinia virus expressing the influenza A virus (IAV) matrix protein but not the replication of IAV in the lung. However, subcutaneous priming followed by intranasal boosting with M1 $1_{58}{ }_{66}$ bearing PLGA microspheres was able to induce vigorous CTL responses both in the lung and spleen of mice which interfered with IAV replication, weight loss, and infection related death. Taken together, vaccination with well defined and highly conserved IAV derived CTL epitopes encapsulated into clinically compatible PLGA microspheres contribute to the control of influenza A virus infections. The promptitude and broad reactivity of the CTL response may help to attenuate pandemic outbreaks of influenza viruses.
\end{abstract}

\section{Introduction}

Influenza viruses circulate all over the world with an annual attack rate of 5 10\% in adults and 20 30\% in children. Influenza virus infection is a serious public health problem that causes worldwide 3 to 5 million cases of severe illness and about 250000 to 500000 deaths per year. Therefore, it is especially recommended for the elderly and children to vaccinate against influenza annually [1]. Currently used vaccines stimulate the production of antibodies directed against viral surface glycoproteins, in particular hemagglutinin (HA) and neuraminidase (NA) [2]. However, due to antigenic drift, these antibodies fail to protect against new antigenic variants of the same type or subtype and are rarely cross reactive against other influenza virus strains [3]. Thus, annual vaccine reformulation is necessary to ultimately maintain immunity against seasonal influenza viruses [4,5]. Furthermore, antigenic drift renders uniform population wide vaccination campaigns, that have led

\footnotetext{
* Corresponding author.

** Correspondence to: M. Groettrup, Division of Immunology, Department of Biology, University of Konstanz, 78457 Konstanz, Germany.

E-mail addresses: Valerie.Herrmann@uni-konstanz.de (V.L. Herrmann),

Carmen.Hartmayer@uni-konstanz.de (C. Hartmayer), oliver.planz@uni-tuebingen.de

(O. Planz), Marcus.Groettrup@uni-konstanz.de (M. Groettrup).
}

to the control of measles and smallpox, ineffective for influenza virus [6]. Clearly, there is a great need for a vaccine that induces heterosubtypic protection against all influenza A viruses.

This heterosubtypic immunity is generally mediated by cytotoxic $T$ lymphocytes (CTLS) [7]. It was demonstrated before, that patients with measurable $\mathrm{T}$ cell responses were able to clear the virus effectively, even though they lack anti influenza virus specific antibodies for the particular influenza virus subtype [8]. The majority of influenza $A$ virus induced $\mathrm{CD}^{+}{ }^{+}$cytotoxic $\mathrm{T}$ cells are directed against internal virus determinants like the nucleoprotein (NP) and the matrix protein 1 (M1) that are highly conserved [9]. In contrast to antibody responses that are specific for each virus subtype, CTLs exhibit the desired exten sive cross reactivity between different influenza A virus strains that could help to attenuate a new pandemic outbreak of influenza $[8,10]$. As influenza A viruses cause respiratory tract infection, the mucosal surface is the site of initial virus replication. Current vaccines induce serum neutralizing antibodies but only little local immune response after parenteral immunization with inactivated virus. Intranasal immu nization on the other hand was shown to be able to stimulate mucosal immunity and CTL responses, which serve as a first line immune defense by suppressing initial viral replication in the respiratory epitheli um $[7,11,12]$. Nguyen et al. could show that mice immunized with a live nonpathogenic influenza virus strain via the pulmonary route survived 
challenge with a pathogenic influenza strain in contrast to mice that were immunized intravenously or intraperitoneally, which showed only minor protection [13]. CTLs specific for epitopes derived from viral proteins that are highly conserved throughout influenza A virus strains can be induced with the help of synthetic peptides. These peptide vaccines are capable of inducing robust CTL responses and provide several advantages. They can be produced economically on a large scale and be stored lyophilized at room temperature. Additionally, a multi epitope vaccine can protect

A
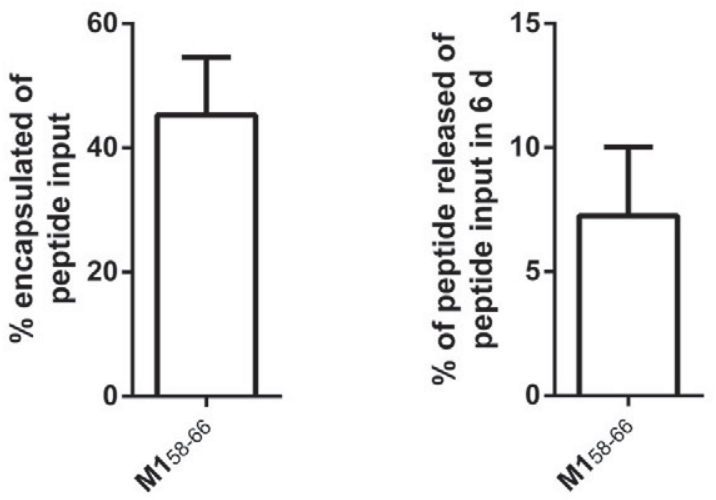

B
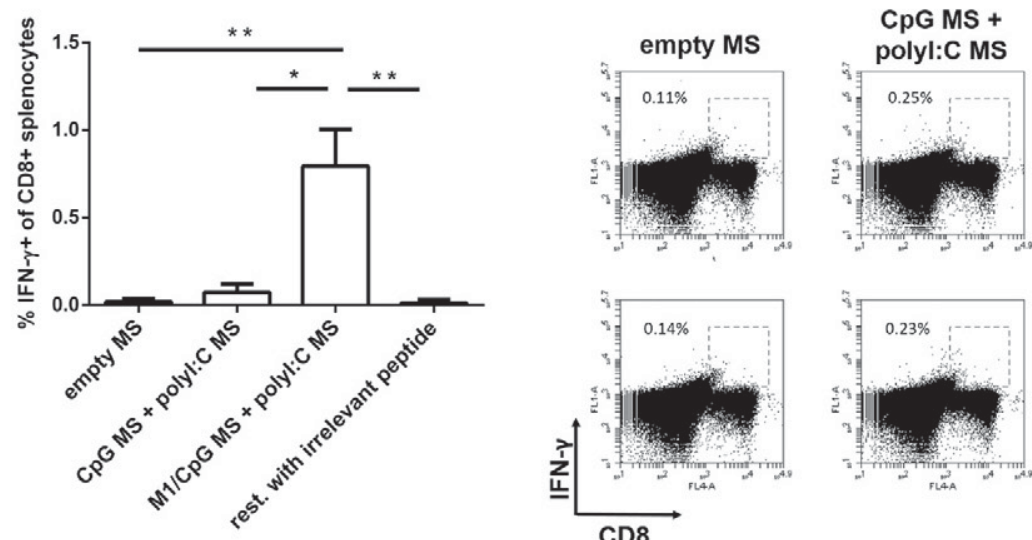

M1/Cpg MS + polyl:C MS
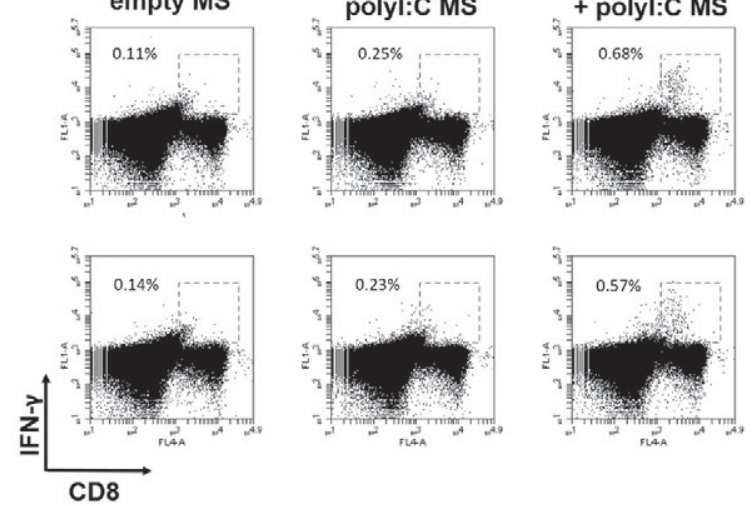

C

D
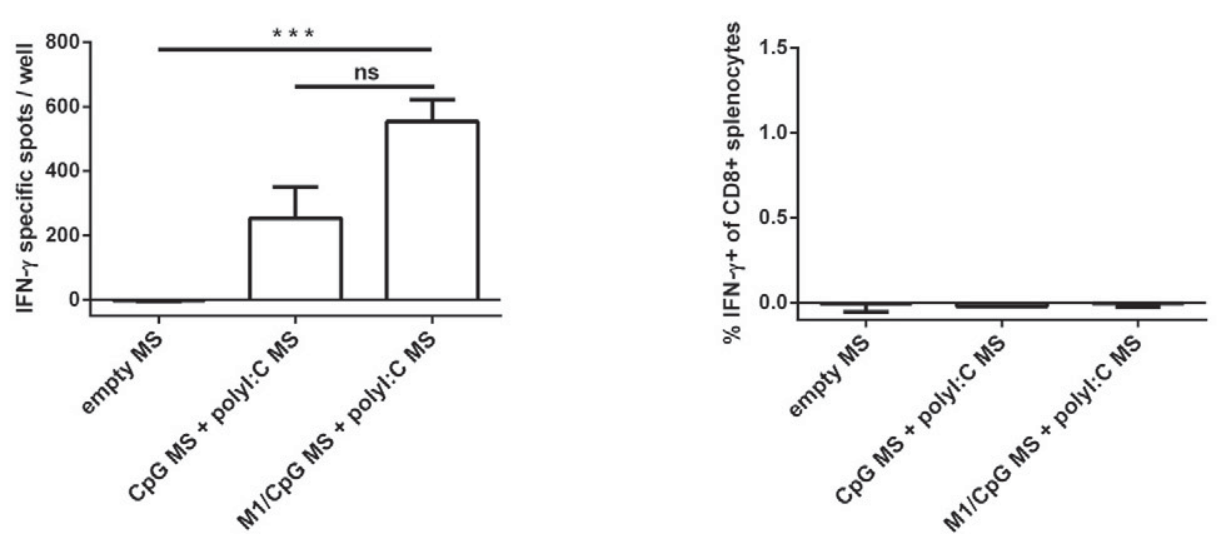

Fig. 1. Production of IFN- $\gamma$ by CD8 ${ }^{+}$T cells after immunization with M1/CpG MS and polyl:C MS. (A) Encapsulation efficiency and release during 6 days in an aqueous medium of M1/CpG containing PLGA MS as determined by BCA assay. Assessed amounts of M1 peptide were compared to theoretical maximal loading and given in \% encapsulation of peptide input (left) and \% of peptide released in aqueous medium during 6 days also based on the peptide input used for particle production (right). (B-D) HLA-A*0201/H-2D ${ }^{d}$ chimera transgenic AAD mice (B/C) $(\mathrm{n}=7 / 6)$ or C57BL/6 wt mice (D) $\left(\mathrm{n}=3\right.$ ) were immunized with $5 \mathrm{mg}$ MS containing $50 \mu \mathrm{g} \mathrm{M} 1_{58} 66$ peptide and $25 \mu \mathrm{g}$ CpG-ODN and $5 \mathrm{mg}$ MS containing $2.5 \mu \mathrm{g}$ polyI:C. Control groups were immunized with the corresponding amounts of encapsulated CpG and polyl:C $(n(B / C)=6 / 2 ; n(D)=2)$ or empty MS $(n(B / C)=4 / 2 ; n(D)=2)$ in 5 mg MS respectively. After 6 days, splenocytes were isolated and analyzed for IFN- $\gamma$ production after peptide restimulation by ICS (B/D) or ELISPOT (C). The numbers next to the gates in the representative dot plots in (B) show IFN- $\gamma^{+}$of $\mathrm{CD}^{+}$cells. Background levels (no peptide) were subtracted. Values (mean $\pm \mathrm{SEM}$ ) in (B/D) are given in percent IFN- $\gamma^{+}$of CD8 ${ }^{+}$lymphocytes. The p values of (B) were calculated by an unpaired t-test with Welsch's correction $\left({ }^{* *} \mathrm{p}=0.0098 ;{ }^{* *} \mathrm{p}=0.0093,{ }^{*} \mathrm{p}=0.0129\right)$. Values (mean $\left.\pm \mathrm{SEM}\right)$ in $(\mathrm{C})$ are given as IFN- $\gamma$ specific spots/well. The $\mathrm{p}$ value was calculated by an unpaired t-test with Welsch's correction $\left.{ }^{* * *} \mathrm{p}=0.0004\right)$. 
against antigenic drift and increase the clonality of the T cell response. In contrast to many live or attenuated vaccines, peptide based vaccines are devoid of infectious material $[11,14,15]$. However, vaccination with pep tides instead of virus via the mucosal route bears the danger of in ducing tolerance or hypersensitivity, as most antigens introduced are poorly immunogenic. A prerequisite for a successful vaccination is therefore the use of adjuvants and an effective delivery system [16].

We and others have investigated biodegradable poly(D,L lactide co glycolide) microspheres (PLGA MS) as antigen delivery systems targeting dendritic cells (DCs) and macrophages in vitro and in vivo [17, 18]. Encapsulated peptides are protected from proteolytic degradation and delivered to phagocytic cells in a targeted and prolonged manner [19 21]. As the induction of CTL responses is difficult to achieve with peptides alone, the addition of potent immune enhancing adjuvants like cytosine phosphorothioate guanine oligodeoxynucleotides (CPG ODN) or polyriboinosinic:polyribocitidylic acid (polyl:C) is necessary. For the generation of a potent immune response TLR ligand and antigen need to be coencapsulated into the same PLGA MS to end up in the same endosome [22].

In the present study, we established a potent CTL based immuniza tion protocol against pandemic influenza A virus (H1N1pdm09) using biodegradable PLGA MS. We found that immunization with PLGA MS encapsulating the antigenic peptide $\mathrm{M} 1_{58-66}$ elicits strong and sustained CTL responses. To prevent antigenic drift more than one antigenic peptide could be encapsulated into the same PLGA MS. Furthermore, we could show that the immunization route is critical for the vaccination efficiency and depends on the infection route of each virus. For protection against influenza A virus, we optimized the immunization protocol to a subcutaneous prime vaccination followed by an intranasal boost vaccina tion. This vaccination reduced disease severity in our experiments and hence might help to control pandemic outbreaks of influenza A virus.

\section{Materials and methods}

\subsection{Preparation of microspheres}

MS were prepared from 14 kDa PLGA 50:50 carrying hydroxyl and carboxyl end groups (Resomer® RG502H, Evonik Röhm GmbH). The peptides $\mathrm{M}_{58-66}$ and $\mathrm{PA}_{46-54}$ from influenza $\mathrm{A}$ virus and TLR ligands were microencapsulated by spray drying as described elsewhere [23]. Briefly, 2.5, 5, 10 or $20 \mathrm{mg} \mathrm{M} \mathrm{M}_{58-66}$ peptide and $5 \mathrm{mg} \mathrm{CpG}$ oligodeoxynucleotides with a phosphorothioate backbone (CpG ODN 1826, Microsynth) or $0.5 \mathrm{mg}$ polyl:C (Sigma Aldrich) were dissolved in $0.5 \mathrm{ml} 0.1 \mathrm{M} \mathrm{NaHCO}_{3}$ and mixed with $1 \mathrm{~g}$ of PLGA dissolved in $20 \mathrm{ml}$ dichloromethane. Coencapsulation of $\mathrm{M}_{58-66}$ and $\mathrm{PA}_{46-54}$ peptides was performed by co dissolving $10 \mathrm{mg} \mathrm{M} 1_{58-66}$ and $10 \mathrm{mg}$ $\mathrm{PA}_{46-54}$ with $5 \mathrm{mg} \mathrm{CpG}$ ODN in $0.5 \mathrm{ml}$ of $0.1 \mathrm{M} \mathrm{NaHCO}_{3}$ and $1 \mathrm{~g}$ PLGA in $20 \mathrm{ml}$ dichloromethane. The aqueous and the organic phase were homogenized under ultrasonication. The obtained $\mathrm{w} / \mathrm{o}$ dispersion was immediately spray dried (Mini Spray dryer 191, Büchi) at a flow rate of $2 \mathrm{ml} / \mathrm{min}$ and inlet/outlet temperature of $40{ }^{\circ} \mathrm{C} / 37^{\circ} \mathrm{C}$. The obtained MS were washed out of the spray dryer's cyclone with $0.05 \%$ poloxamer 188 (Synperonic®F68, Serva Electrophoresis), collected on a cellulose acetate membrane filter and dried under reduced pressure (20 mbar) for $18 \mathrm{~h}$ at room temperature. MS were stored at $4{ }^{\circ} \mathrm{C}$. Immediately before use, MS were dispersed in PBS by ultrasonication for $30 \mathrm{~s}$ to obtain a homogenous MS solution.

\subsection{Characterization of the microspheres}

To characterize the PLGA MS, encapsulation efficiency and release of the two peptides was analyzed. For the determination of the encapsula tion efficiency, $5 \mathrm{mg}$ MS were dissolved in $200 \mu \mathrm{l}$ acetone. The solvent
A

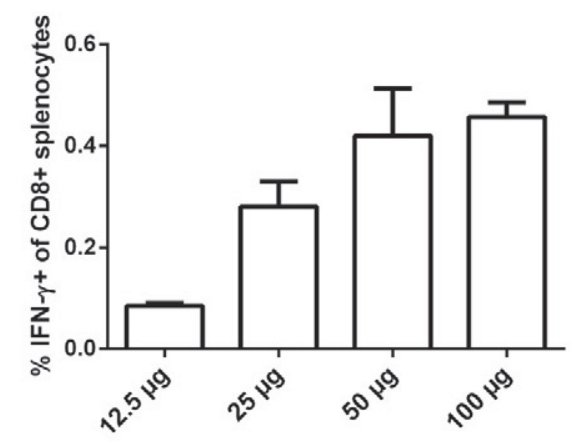

C

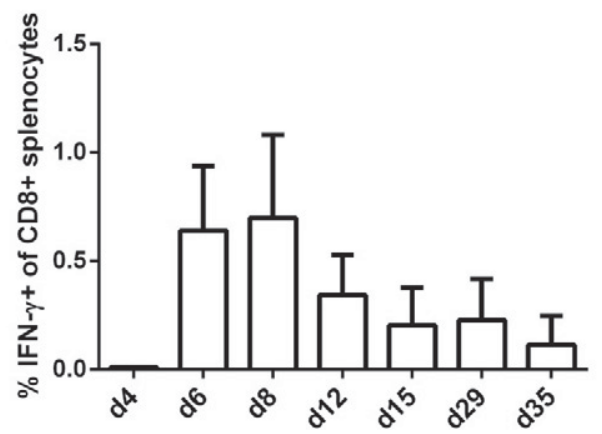

B

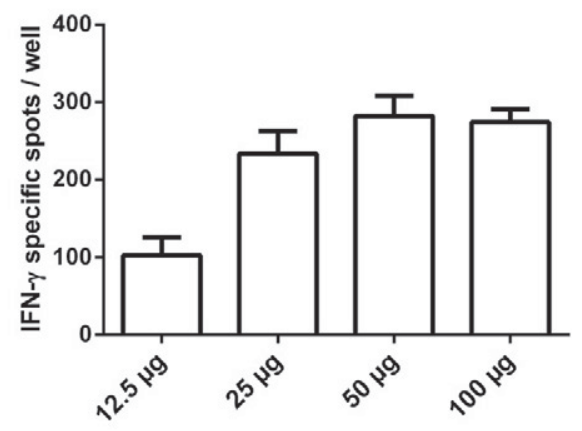

Fig. 2. Titration of the peptide amount and kinetics of the CTL response after immunization with M1/CpG MS and polyI:C MS. (A, B) AAD mice ( $n=3$ ) were immunized s.c. with 5 mg MS containing $100 \mu \mathrm{g} ; 50 \mu \mathrm{g} ; 25 \mu \mathrm{g}$ or $12.5 \mu \mathrm{g} \mathrm{M} 1_{58}{ }_{6}$ peptide and $25 \mu \mathrm{g}$ CpG-ODN and $5 \mathrm{mg}$ MS containing $2.5 \mu \mathrm{g}$ polyl:C. After 6 days, splenocytes were isolated and analyzed for IFN- $\gamma$ production after peptide restimulation by ICS (A) or ELISPOT (B). Background levels (no peptide) were subtracted. Values (mean \pm SEM) are given in percent IFN- $\gamma^{+}$of CD8 ${ }^{+}$lymphocytes. (C) AAD mice were immunized s.c. with 5 mg MS containing $50 \mu \mathrm{g} \mathrm{M1} 1_{58} 66$ peptide and $25 \mu \mathrm{g}$ CpG-ODN and 5 mg MS containing $2.5 \mu \mathrm{g}$ polyl:C. After 4 ( $\mathrm{n}=2$ ); 6 ( $\mathrm{n}=5$ ); 8 ( $\mathrm{n}=5$ ); 12 $(\mathrm{n}=5), 15(\mathrm{n}=5), 29(\mathrm{n}=4)$ and $35(\mathrm{n}=4)$ days splenocytes were isolated and analyzed for IFN- $\gamma$ production after peptide restimulation by ICS. Background levels (no peptide) were subtracted. Values (mean \pm SEM) are given in percent IFN- $\gamma+$ of CD8 + lymphocytes. 
was evaporated with vacuum centrifugation and the pellet was resus pended in MilliQ water under ultrasonication. Release of the peptides from the PLGA MS was identified by dispersing $5 \mathrm{mg}$ PLGA MS in $200 \mu \mathrm{l}$ PBS by ultrasonication for $30 \mathrm{~s}$. After incubation at $37^{\circ} \mathrm{C}$ under agitation for 6 days, samples were spun down. Peptide contents of the supernatants were determined using the MicroBCA ${ }^{\mathrm{TM}}$ Protein Assay Kit (Life Technolo gies) according to the manufacturer's protocol using the respective peptide as standard. The assessed amounts were compared to theoretical maximal loading and given in \% encapsulation efficiency.

\subsection{Mice and immunizations}

HLA A*0201 transgenic mice (AAD mice) were originally obtained from Charles River Laboratories. All mice were kept in a specific pathogen free facility and used at 612 weeks of age. Animal experiments were conducted by trained researchers in accordance with the guidelines of the Federation of the European Laboratory Science Associations. All animal experiments in this study were approved by the Review Board of Regierungspräsidium Freiburg, Freiburg, Germany (permission number G 14/128). For s.c. vaccination, a mixture of $5 \mathrm{mg}$ MS containing
M1 $1_{58-66}$ and/or $\mathrm{PA}_{46-54}(50 \mu \mathrm{g})$ and $\mathrm{CpG}$ ODN $(25 \mu \mathrm{g})$ and $5 \mathrm{mg}$ polyl:C MS $(2.5 \mu \mathrm{g})$ were injected in a total volume of $200 \mu \mathrm{l}$ at a single site at the base of the tail. Control groups received $5 \mathrm{mg}$ CpG ODN MS ( $25 \mu \mathrm{g})$ and $5 \mathrm{mg}$ polyl:C MS (2.5 $\mu \mathrm{g})$. For i.n. immunizations mice were anesthetized by i.p. injection of $150 \mu \mathrm{l}$ of a ketamine (Sanofi) rompun (Bayer) solution (equal volumes of a $2 \%$ rompun solution and a $10 \%$ ketamine solution were mixed at a rate of 1:10 with PBS). Intranasal vaccination was performed with a mixture of $2.5 \mathrm{mg}$ MS loaded with M1 $1_{58-66}$ and/ or $\mathrm{PA}_{46-54}(25 \mu \mathrm{g})$ and $\mathrm{CpG}$ ODN $(12.5 \mu \mathrm{g})$ and $2.5 \mathrm{mg}$ polyl:C MS $(1.25 \mu \mathrm{g})$ in $50 \mu \mathrm{l}$ PBS $(25 \mu \mathrm{l}$ per nostril). Control groups received $2.5 \mathrm{mg}$ CpG ODN MS (12.5 $\mu \mathrm{g})$ and $2.5 \mathrm{mg}$ polyl:C MS (1.25 $\mu \mathrm{g})$.

\subsection{Viruses}

Recombinant vaccinia viruses coding for M1 (rVV M1) and M1 $1_{58-66}$ (rVV ESM1) were kindly provided by Jonathan Yewdell (NIH, Bethesda, MD) and propagated on BSC 40 cells. The human pandemic influenza virus strain A/Regensburg/D6/09 (H1N1pdm09, RB1) was obtained from the Robert Koch Institute, Federal Institute for Public Health,
A

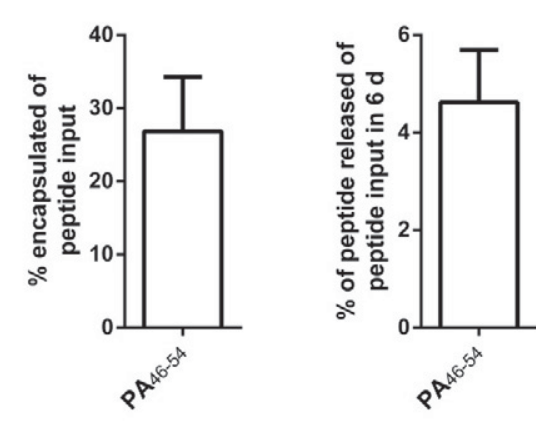

C

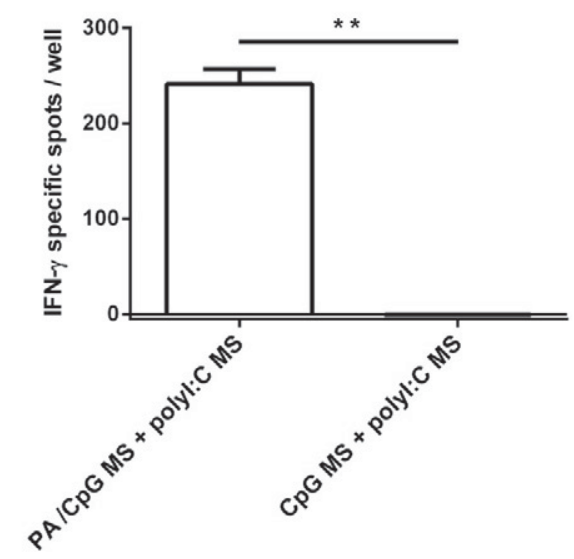

B

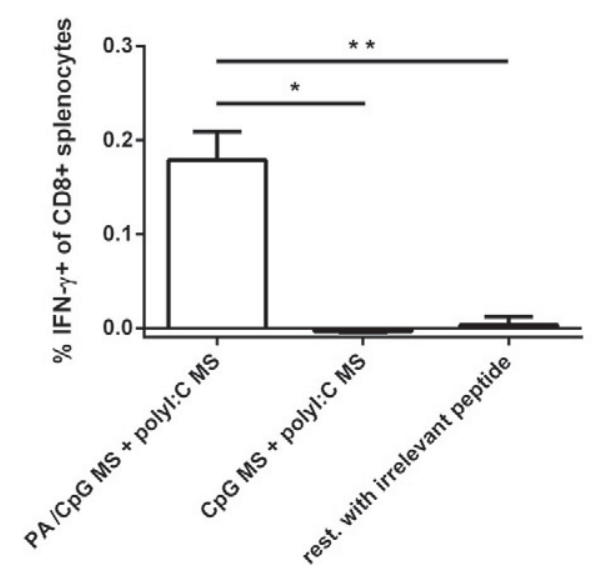

D

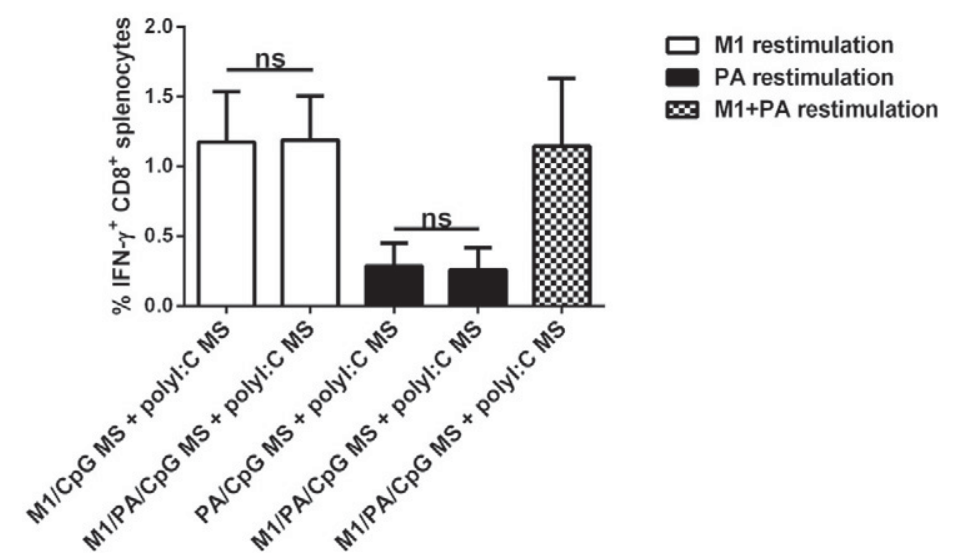

Fig. 3. CTL responses elicited after immunization with $\mathrm{PA} / \mathrm{CpG}$ MS and polyI:C MS or co-encapsulated M1/PA/CpG MS and polyI:C MS. (A) Encapsulation efficiency and release during 6 days in aqueous medium of PA/CpG containing PLGA MS as determined by BCA assay. Assessed amounts of PA peptide were compared to theoretical maximal loading and given in $\%$ encapsulation of peptide input (left) and \% of peptide released in aqueous medium during 6 days also based on the peptide input used for particle production (right). (B/C) AAD mice $(\mathrm{n}=3$ ) were immunized s.c. with $5 \mathrm{mg}$ MS containing $50 \mu \mathrm{g} \mathrm{PA} 4654$ peptide and $25 \mu \mathrm{g}$ CpG-ODN and 5 mg MS containing $2.5 \mu \mathrm{g}$ polyl:C. The control group was immunized with the corresponding amounts of encapsulated $\mathrm{CpG}$ and polyl:C in MS $(\mathrm{n}=2)$. After 6 days, splenocytes were isolated and analyzed for IFN- $\gamma$ production after peptide restimulation by ICS (B)/ ELISPOT (C). Background levels (no peptide) were subtracted. Values (mean \pm SEM) in (B) are given in percent IFN- $\gamma^{+}$of CD8 ${ }^{+}$lymphocytes. The p value of (B) was calculated by an unpaired t-test $\left({ }^{*} \mathrm{p}=0.0184\right)$. Values (mean $\pm \mathrm{SEM}$ ) in $(\mathrm{C})$ are given as IFN- $\gamma$ specific spots/well. The $\mathrm{p}$ value was calculated by an unpaired $\mathrm{t}$-test $\left.{ }^{* *} \mathrm{p}=0.0013\right)$. $(\mathrm{D}) \mathrm{AAD}$ mice $(\mathrm{n}=6)$ were immunized s.c. with $5 \mathrm{mg}$ MS containing $50 \mu \mathrm{g} \mathrm{PA}{ }_{46}{ }_{54}, 50 \mu \mathrm{g} \mathrm{M} 1_{58} 66$ peptide and $25 \mu \mathrm{g}$ CpG-ODN and 5 mg MS containing $2.5 \mu \mathrm{g}$ polyl:C. The control group was immunized with the corresponding amounts of encapsulated M1 or PA and CpG in 5 mg MS and polyl:C MS. After 6 days, splenocytes were isolated and analyzed for IFN- $\gamma$ production after restimulation with M1 and/or PA peptide as indicated by ICS. Background levels (no peptide) were subtracted. Values (mean \pm SEM) are given in percent IFN- $\gamma^{+}$of CD8 ${ }^{+}$lymphocytes. 
Berlin, Germany. The virus was further propagated in human lung adenocarcinoma epithelial cells (A549).

\subsection{Isolation of cells}

Splenocytes were isolated by mechanical disruption. For isolation of lung lymphocytes, lungs were washed with PBS, cut into small pieces and digested at $37^{\circ} \mathrm{C}$ in IMDM containing $0.2 \mathrm{mg} / \mathrm{ml}$ of collagenase D (Roche), $0.2 \mathrm{mg} / \mathrm{ml}$ of DNase I (Roche), 10\% FCS, $100 \mathrm{U} / \mathrm{ml} \mathrm{P/S}$ for $45 \mathrm{~min}$ at $37^{\circ} \mathrm{C}$ under agitation. Cells were gently pressed through a mesh, washed and re suspended in 36\% Percoll ${ }^{\circledR}$ in PBS (Sigma Aldrich). The cell suspension was gently overlaid onto 70\% Percoll ${ }^{\circledR}$ and centrifuged for $30 \mathrm{~min}$ at $1.350 \times \mathrm{g}$ at $4{ }^{\circ} \mathrm{C}$. Lymphocytes were collected from the interface.

\subsection{Intracellular cytokine staining}

Intracellular cytokine staining (ICS) was performed to detect intracellular interferon gamma (IFN $\gamma$ ) as a measure of CTL activation. Isolated splenocytes or lung lymphocytes were incubated with or without $10 \mu \mathrm{M}$ of the respective peptide or an irrelevant control peptide in the presence of $10 \mu \mathrm{M} / \mathrm{ml}$ brefeldin A (Sigma Aldrich) for $5 \mathrm{~h}$ at $37^{\circ} \mathrm{C}$. After washing, the cells were stained with APC conjugated rat anti mouse $\mathrm{CD} 8 \alpha$ antibody clone 536.7 (eBioscience) for $20 \mathrm{~min}$ at $4{ }^{\circ} \mathrm{C}$. The cells were washed twice before they were fixed with $4 \%$ paraformaldehyde in PBS for 5 min at $4{ }^{\circ} \mathrm{C}$. Afterwards, cells were washed twice with $\mathrm{PBS} / 0.1 \%$ saponin for permeabilization and were then labeled intra cellularly with FITC conjugated rat anti IFN $\gamma$ antibody (clone XGM1.2) in PBS $/ 0.1 \%$ saponin overnight at $4{ }^{\circ} \mathrm{C}$. The next day, cells were washed twice and were resuspended in PBS for flow cytometry. Background values of each sample (no restimulation with peptide) were subtracted.

\subsection{ELISPOT}

A commercially available antibody pair (BD Biosciences) for the detection of IFN $\gamma$ producing cells was used according to the manufacturer's protocol. ELISPOT 96 well plates were coated with anti IFN $\gamma$ antibody and subsequently blocked. Splenocytes were incu bated with or without $10 \mu \mathrm{M}$ of the respective peptide overnight. After incubation with a biotinylated antibody for $2 \mathrm{~h}$, a streptavidin alkaline phosphatase enzyme conjugate was added for $40 \mathrm{~min}$ at room tempera ture. Spots of the dried plate were counted using an ImmunoScan instru ment (C.T.L., Cellular Technology Ltd.).

\subsection{Vaccinia virus infection and protection assay}

To assay viral protection, AAD mice were immunized s.c. with a mixture of $5 \mathrm{mg}$ MS loaded with M158-66 peptide (50 $\mu \mathrm{g})$ and $\mathrm{CpG}$ ODN $(25 \mu \mathrm{g})$ and $5 \mathrm{mg}$ polyl:C MS $(2.5 \mu \mathrm{g})$. On day 6 after immunization mice were challenged i.p. with $2 \times 10^{6}$ pfu recombinant vaccinia virus coding for M1 $1_{58-66}$ (rVV ESM1). Four days later, ovaries were taken, sin gle cell suspensions were prepared by physical disruption in MEM, 5\% FCS and analyzed by plaque assay after 6 freeze thaw cycles. Suspensions were titrated and added to confluent BSC 40 cells. After infection, BSC 40 cells were incubated for $24 \mathrm{~h}$ at $37^{\circ} \mathrm{C}, 5 \% \mathrm{CO}_{2}$. After removal of the medium, plaques were visualized by addition of $0.5 \%$ crystal violet solution for $1 \mathrm{~h}$, counted, and the pfu were calculated.

\subsection{Influenza virus infection}

On day 6 after the last MS immunization, mice were anesthetized by intraperitoneal injection of $150 \mu \mathrm{l}$ of a ketamine (Sanofi) rompun (Bayer) solution (equal volumes of a $2 \%$ rompun solution and a $10 \%$ ketamine solution were mixed at the rate of $1: 10$ with PBS), before intranasal inoculation with the influenza $A$ virus strain $A$ / Regensburg/D6/09 (H1N1pdm09, RB1). For infection, a $10 \times 50 \%$ mouse lethal dose $\left(M^{2} D_{50}\right)$ was used $\left(10 \times\right.$ MLD $_{50}=5 \times 10^{4} \mathrm{pfu}$ in $\mathrm{C} 57 \mathrm{BL} / 6$ mice). For determination of the clinical score, the following disease symptoms were found and defined: ruffled fur, teeth crunching, ataxia, dyspnea and conjunctivitis. If mice showed one of the aforementioned symptoms they received one score; 2 symptoms $=$ score $2 ; 3$ and more symptoms $=$ score 3 and death $=$ score 4 . Note, score 4 was kept throughout the observation period. Score represents the mean value of the group. Furthermore, mice were weighted daily. When mice were euthanized at the clinical end point of $75 \%$ of the initial bodyweight, the bodyweight at the endpoint was kept throughout the observation period.
A

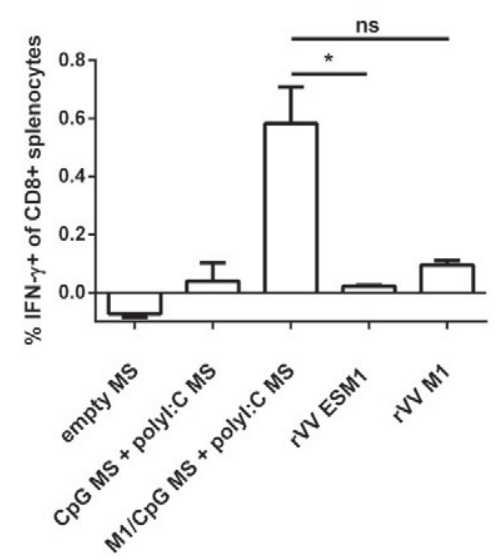

B

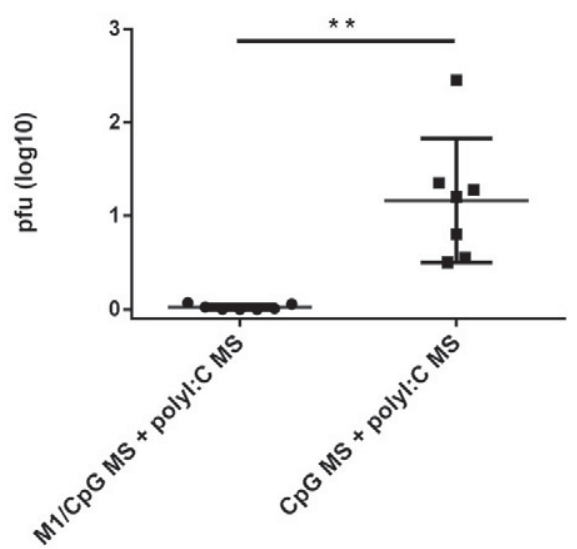

Fig. 4. Comparison of the CTL response after immunization with $M 1 / C p G M S$ and polyl:C MS or infection with recombinant vaccinia virus and induction of protective immunity. (A) AAD mice $(n=5)$ were immunized s.c. with $5 \mathrm{mg}$ MS containing $50 \mu \mathrm{g} \mathrm{M} 1_{58}$ 66 peptide and $25 \mu \mathrm{g}$ CpG-ODN and $5 \mathrm{mg}$ MS containing $2.5 \mu \mathrm{g}$ polyI:C or infected i.p. with $2 \times 10^{6}$ pfu rVV ESM1 (encoding the T cell epitope M1 1586 ) or rVV M1 (encoding the influenza virus matrix 1 protein). Control groups were immunized with the corresponding amounts of encapsulated CpG and polyl:C in MS $(n=3)$ or empty MS ( $n=3)$. After 6 days, splenocytes were isolated and analyzed for IFN- $\gamma$ production after peptide restimulation by ICS. Background levels (no peptide) were subtracted. Values (mean $\pm \mathrm{SEM}$ ) are given in percent IFN- $\gamma^{+}$of $\mathrm{CD}^{+}$lymphocytes. The $\mathrm{p}$ value was calculated by an unpaired $\mathrm{t}$-test with Welsch's correction $\left({ }^{*} \mathrm{p}=0.0114\right)$. (B) AAD mice ( $\mathrm{n}=7$ ) were immunized s.c. with either $5 \mathrm{mg}$ MS containing $50 \mu \mathrm{g} \mathrm{M1} 1_{58} 66$ peptide and $25 \mu \mathrm{g}$ CpG-ODN and $5 \mathrm{mg}$ MS containing $2.5 \mu \mathrm{g}$ polyl:C or $5 \mathrm{mg}$ CpG MS and 5 mg polyI:C MS containing corresponding amounts. Six days after vaccination, mice were challenged i.p. with $2 \times 10^{6} \mathrm{pfu}$ rVV ESM1, and 4 days later virus titers were determined in ovaries. Individual mice and the median values per group are shown. The p value was calculated by an unpaired t-test with Welsch's correction $\left({ }^{* *} \mathrm{p}=0.0040\right)$. 


\subsection{Influenza virus plaque assay}

To assess the number of infectious particles in the lungs, a plaque assay using AVICEL ${ }^{\circledR}$ was performed in 96 well plates as described previously [24] $48 \mathrm{~h}$ after infection. Briefly, Madin Darby canine kidney (MDCK II) cells were grown to confluency in 96 well dishes, then they were washed with PBS and infected with serial dilutions of the superna tants in PBS/BA for 30 min at $37^{\circ} \mathrm{C}$. After incubation, cells were overlaid with overlay medium [1:1, MEM medium containing $0.2 \%$ BSA, antibiotics and 2.5\% AVICEL ${ }^{\circ}$ Medium (FMC BioPolymer)] for $24 \mathrm{~h}$. Afterwards, virus infected cells were immunostained by incubating for $1 \mathrm{~h}$ with a monoclonal antibody specific for the influenza $\mathrm{A}$ virus nucleoprotein (Serotec), followed by 30 min incubation with peroxidase labeled anti mouse antibody (DIANOVA) and $10 \mathrm{~min}$ incubation with True Blue ${ }^{\mathrm{TM}}$ peroxidase substrate (KPL). Stained plates were scanned on a flatbed scanner and the data were acquired by Corel DRAW 9.0 software. Viral titers are shown as the logarithm to the base 10 of the mean values.

\subsection{Statistics}

For statistical analyses, groups from similar experiments were pooled and analyzed for significant differences as indicated in the graph. The p values for experiment composites are given in the figure legends. All statistical analyses were performed using Prism software (GraphPad Software, Inc.).

\section{Results}

3.1. High immunogenicity of PLGA MS based immunization with the influenza A virus epitope $M 1_{58-66}$

To investigate the feasibility and potency of eliciting CTL responses to influenza A virus the highly conserved synthetic $\mathrm{M} 1_{58-66}$ peptide epitope of influenza virus matrix 1 protein was encapsulated together with the CpG oligodesoxynucleotide 1826 into biodegradable PLGA microspheres. First of all, the generated M1/CpG MS were characterized regarding their peptide encapsulation efficiency and peptide release. Compared to the theoretical maximal loading, around $45 \%$ of the peptide was encapsulated into the MS and during the first 6 days around $7 \%$ of the peptide was released in aqueous medium (Fig. 1A). Next, the immunogenicity of an immunization with these MS was addressed. For this purpose HLA A*0201 transgenic AAD mice were s.c. immunized with a mixture of $M 1_{58-66} / \mathrm{CpG}$ MS and polyI:C MS. Six days after the immunization, a strong induction of antigen specific CTLs was measureable in the spleen (Fig. $1 \mathrm{~B}+\mathrm{C}$ ). While immunization with microspheres containing only the adjuvants $\mathrm{CpG}$ ODN and polyl:C induced only a minor response due to unspecific stimulation, no IFN $\gamma$ secretion was detectable after immunization with empty microspheres. In contrast, no IFN $\gamma$ producing, antigen specific CTLs could be induced in C57BL/6 mice emphasizing the HLA A*0201 restriction of the M158-66 epitope (Fig. 1D). These data show the high immunogenic potential of a PLGA MS based immunization with the influenza virus epitope M158-66 and the Th1 polarizing TLR ligands CpG ODN and polyI:C.

\subsection{MS induce strong and sustained immune responses in vivo}

To determine the optimal peptide amount for vaccination with PLGA MS, AAD mice received a single injection of MS containing $12.5,25$, 50 or $100 \mu \mathrm{g} \mathrm{M} 1_{58-66}$ peptide co encapsulated with $25 \mu \mathrm{g}$ CpG ODN in a mixture with polyI:C MS $(2.5 \mu \mathrm{g})$. The lowest peptide concentration already induced a robust immune response in the spleens of immunized mice after 6 days (Fig. $2 \mathrm{~A}+\mathrm{B}$ ). The number of $\mathrm{M} 1_{58-66}$ specific, IFN $\gamma$ secreting $\mathrm{CD}^{+} \mathrm{T}$ cells increased corresponding to the peptide amount encapsulated in the MS until a plateau was reached for a peptide concentration of $50 \mu \mathrm{g}$ per mouse. The MS containing $100 \mu \mathrm{g} \mathrm{M1} 1_{58-66}$ peptide did not induce a higher immune response, which could be due to a limited encapsulation efficacy or a peptide saturation of the T cells. As a further characteristic of MS based vaccination the immune response kinetics were analyzed (Fig. 2C). Therefore, AAD mice were immunized with an optimal peptide concentration of $50 \mu \mathrm{g} \mathrm{M} 1_{58-66}$ peptide per mouse. On day four after immunization, no peptide specific CTLs were detectable. The peak of the immune response could be measured between day 6 and day 8 . There was a decreasing but persistent CTL response at least until the last time point of the measurement on day 35 . The best vaccination protocol was found to be an immunization of the AAD mice with MS containing $50 \mu \mathrm{g} \mathrm{M}_{58-66}$ peptide and CpG ODN $(25 \mu \mathrm{g})$ in combination with polyl:C MS $(2.5 \mu \mathrm{g})$.

\subsection{Co encapsulation of two peptide antigens does not diminish the elicited immune response}

Immune escape by antigenic drift reduces the reliability of vaccination against influenza virus. Therefore, it is advantageous to encapsulate more

A

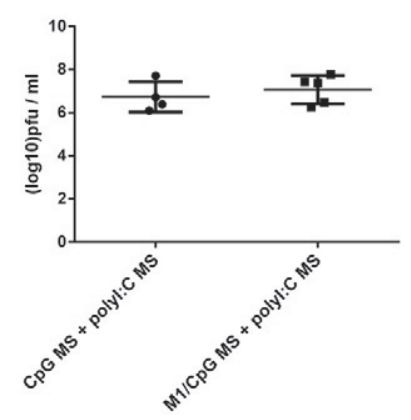

B

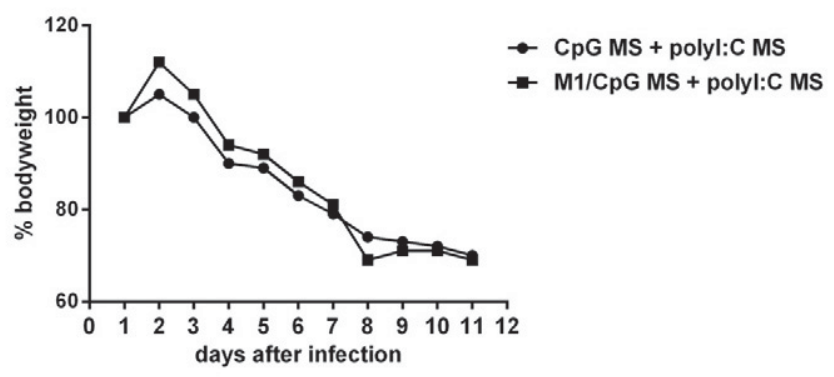

C

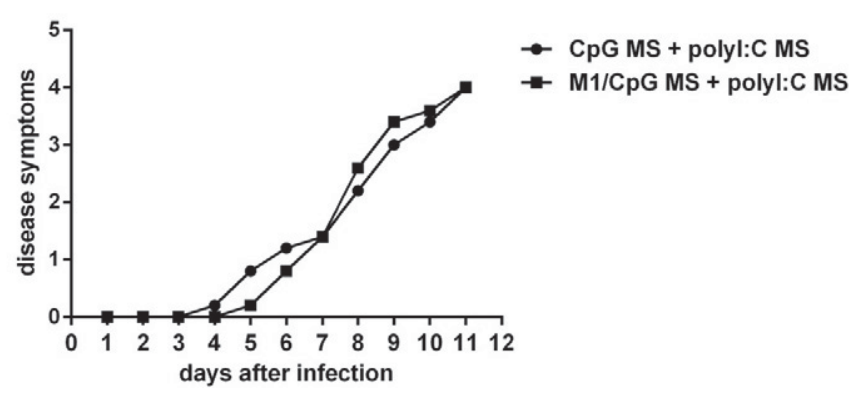

Fig. 5. Failure to induce influenza virus protective immunity solely by subcutaneous PLGA MS-based vaccination. (A) AAD mice $(\mathrm{n}=5$ ) were immunized s.c. with $5 \mathrm{mg}$ MS containing $50 \mu \mathrm{g} \mathrm{M} 1_{58}{ }_{66}$ peptide and $25 \mu \mathrm{g}$ CpG ODN and $5 \mathrm{mg}$ MS containing $2.5 \mu \mathrm{g}$ polyl:C. The control group was immunized with corresponding amounts of encapsulated $\mathrm{CpG}$ and polyI:C. Six days after vaccination, mice were challenged i.n. with $5 \times 10^{4}$ pfu RB1 H1N1pdm09 influenza virus (RB1). $48 \mathrm{~h}$ after infection, lungs were recovered for determination of the virus titer. Individual mice and the median values per group are shown. Disease symptoms (B) and bodyweight (C) were monitored during a time period of 11 days after infection. Median values per group are shown. 
than one peptide antigen into MS. As it was shown before that antigen and the Toll like receptor ligand need to be co encapsulated into one MS [22] we tested if two peptide antigens can be encapsulated together with CpG ODN into one MS with the same efficacy. $\mathrm{PA}_{46-54}$ derived from the RNA polymerase was used as a second peptide, which like M1 $1_{58-66}$ is a naturally processed, HLA A*0201 restricted and highly conserved epitope of influenza virus [25]. First of all, we could show that $27 \%$ of the theoretical maximal loading of $\mathrm{PA}_{46-54}$ was encapsulated into the MS and $9 \%$ of the maximal loading was released during incuba tion at $37^{\circ} \mathrm{C}$ for 6 days from $\mathrm{PA}_{46-54} / \mathrm{CpG}$ MS (Fig. 3A). $\mathrm{PA}_{46-54} / \mathrm{CpG}$ MS mixed with polyI:C MS were highly immunogenic in AAD mice and induced a strong peptide specific CTL response in spleens of vaccinated mice (Fig. 3B + C). Thus, AAD mice were immunized with MS charged with $\mathrm{M} 1_{58-66}$ peptide ( $50 \mu \mathrm{g}$ ), $\mathrm{PA}_{46-54}$ peptide ( $50 \mu \mathrm{g}$ ), and CpG ODN $(25 \mu \mathrm{g})$ and co injected with polyl:C MS $(2.5 \mu \mathrm{g})$. Splenocytes were briefly restimulated ex vivo with either $\mathrm{M}_{58-66}$ peptide or $\mathrm{PA}_{46-54}$ peptide and numbers of IFN $\gamma^{+} \mathrm{CD}^{+}$cells were compared to those of splenocytes of AAD mice injected with MS containing only one of the peptides. Both, $\mathrm{M}_{58-66}$ and $\mathrm{PA}_{46-54}$ singly charged MS induced strong CTL responses with $\mathrm{M} 1_{58-66}$ MS being more potent. The MS containing both peptide antigens elicited similar CTL responses as the MS carrying only one peptide. For restimulation with both peptides no synergistic effects were detectable (Fig. 3D). Accordingly, co encapsulation of two peptide epitopes into the same MS did not diminish the elicited CTL responses to each of them.

3.4. Vaccination with PLGA MS protects mice from infection with a recom binant vaccinia virus

In the first instance, we compared the potency of a PLGA MS based vaccination to an immune response elicited by a viral infection. Therefore, AAD mice were immunized with MS carrying $\mathrm{M}_{58-66}$ peptide and CpG ODN mixed with polyI:C MS or were infected with a recombinant vaccinia virus coding for the M1 protein (rVV M1) or the M1 $1_{58-66}$ epitope (rVV ESM1). While immunization with PLGA MS induced a strong and robust CTL response, a rather low response was recorded after infection with the recombinant vaccinia virus (Fig. 4A).

\section{A}

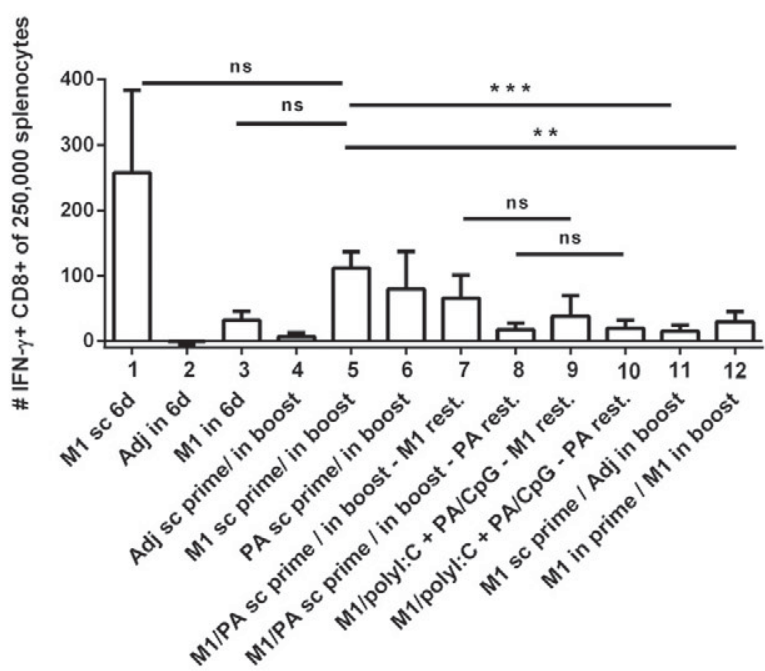

Infection with vaccinia virus is a good model for investigating immune mediated viral protection, as it depends on the activity of CTLs. Hence, we compared the antiviral capacity of mice immunized with $\mathrm{M} 1_{58-66} / \mathrm{CpG}$ containing MS and polyI:C MS with control mice that received CpG MS and polyI:C MS. Mice were challenged with $1 \times 10^{6}$ pfu vaccinia virus on day 6 after immunization and virus titers were determined 4 days later in the ovaries. Vaccination with M158-66/CpG MS and polyI:C MS led to a complete clearance of vaccinia virus (Fig. 4B). In contrast, control mice showed high rVV ESM1 titers in the ovaries. Taken together, vaccination with PLGA MS induced protection against vaccinia virus in an antigen specific manner.

\subsection{Single vaccination with PLGA MS does not allay influenza virus infection}

Protective immunity against influenza virus after vaccination and natural infection is primarily mediated by antibody responses against viral surface proteins. However, reduced disease severity can be achieved with strong $T$ cell responses to internal viral proteins [26]. After having successfully demonstrated the antiviral capacity of PLGA MS in a vaccinia virus infection model, we investigated whether vaccination with PLGA MS can also temper influenza virus infection. To test this, mice were immunized either with PLGA MS containing $\mathrm{M} 1_{58-66} / \mathrm{CpG}$ and polyI:C MS or with CpG MS and polyI:C MS as a control for antigen specificity. Six days after immunization mice were inoculated intranasally (i.n.) with $5 \times 10^{4}$ pfu H1N1pdm09 influenza virus. After $48 \mathrm{~h}$ lungs of mice from both groups were collected and virus titers were determined by plaque assay. There was no reduction of virus titers in the lungs of mice treated with MS containing M1 $1_{58-66}$ compared to the control group (Fig. 5A). Both groups showed a continuous loss of bodyweight starting from day 2 (Fig. 5B). Onset of clinical symptoms was at day 4 post infection evolving to score four (death) in both groups (Fig. 5C). Although s.c. vaccination with PLGA MS has a high immune mediated antiviral capacity during vaccinia virus infection it does not allay influenza virus infection in vivo.

B

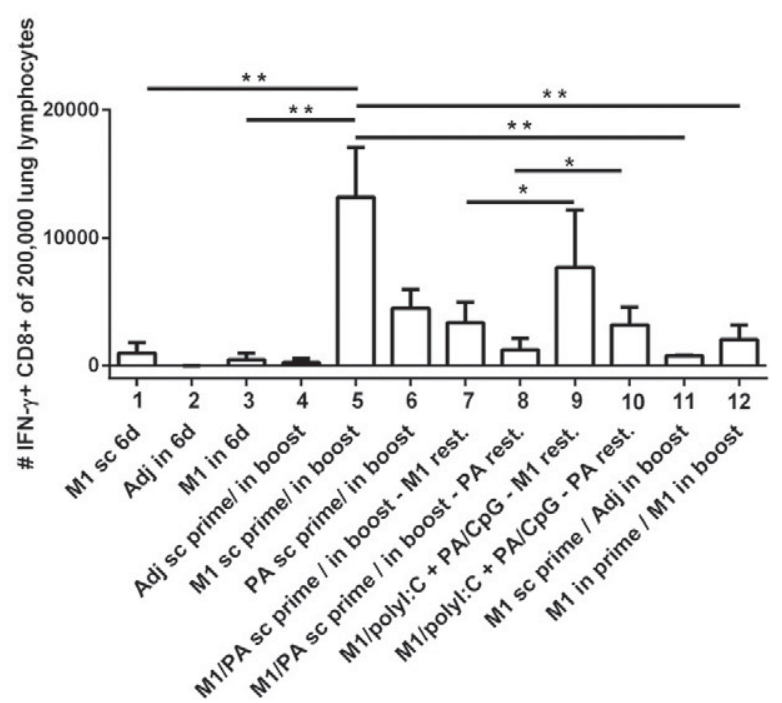

Fig. 6. Subcutaneous priming and intranasal boosting with PLGA MS yields strong CTL responses to influenza virus epitopes in the lung. (A/B) For priming, AAD mice were s.c. immunized with $5 \mathrm{mg} \mathrm{M1/CpG} \mathrm{MS} \mathrm{(} n=6)$, PA/CpG MS or M1/PA/CpG MS each combined with $5 \mathrm{mg}$ polyl:C MS or with M1/polyl:C MS combined with PA/CpG MS. The control group was immunized with the corresponding amounts of $\mathrm{CpG}$ MS and polyl:C MS $(n=4)$. Boost and single i.n. immunizations were performed with $2.5 \mathrm{mg}$ of the corresponding MS. Six days after the last immunization, splenocytes (A) and lung cells (B) were isolated and analyzed for IFN- $\gamma$ production after peptide restimulation by ICS. Background levels (no peptide) were subtracted. Values (mean \pm SEM) are given in (A) as counts of IFN- $\gamma^{+} \mathrm{CD}^{+}$cells of 250000 counted splenocytes and in (B) as counts of IFN- $\gamma^{+} \mathrm{CD} 8^{+}$cells of 200000 lung leukocytes. The p values were calculated by an unpaired t-test with Welsch's correction $\left((\mathrm{A}){ }^{* *} \mathrm{p}=0.0012,{ }^{* * *} \mathrm{p}=0.0004\right),\left((\mathrm{B}){ }^{* *} \mathrm{p}=0.0017,{ }^{* *} \mathrm{p}=0.0017,{ }^{* *} \mathrm{p}=0.002,{ }^{* *} \mathrm{p}=0.0019,{ }^{*} \mathrm{p}=0.00457,{ }^{*} \mathrm{p}=0.0126\right)$. 


\subsection{PLGA MS can induce mucosal and systemic immunity}

Systemic vaccination might not be suitable to induce CTLs against influenza virus at the site of infection, the respiratory tract. To overcome these limitations, we evaluated two alternative immunization strategies with the aim to generate both, mucosal and systemic immunity. For the first vaccination scheme AAD mice were primed s.c. with $5 \mathrm{mg}$ peptide $(50 \mu \mathrm{g}) / \mathrm{CpG}(25 \mu \mathrm{g}) \mathrm{MS}$ and $5 \mathrm{mg}$ polyl:C (2.5 $\mu \mathrm{g}) \mathrm{MS}$ in a volume of $200 \mu \mathrm{l}$ and boosted after $14 \mathrm{~d}$ i.n. with half the amount of MS in a volume of $50 \mu \mathrm{l}$. For the second vaccination strategy, mice were immunized i.n. with peptide $(25 \mu \mathrm{g}) / \mathrm{CpG}(12.5 \mu \mathrm{g}) \mathrm{MS}$ and polyl:C (1.25 $\mu \mathrm{g}) \mathrm{MS}$. The same immunization protocols were applied to the control groups that received CpG MS and polyI:C MS. Six days after the last immunization, the numbers of antigen specific CTLs were analyzed in spleen (Fig. 6A) and lung (Fig. 6B). In the spleen, the highest number of antigen specific CTLs was found for the group that received a single subcutaneous immunization (Fig. 6A, lane 1). A strong CTL response was also observable in the spleens of mice immunized with $\mathrm{M}_{58-66}, \mathrm{PA}_{46-54}$, or $\mathrm{M} 1_{58-66} /$ $\mathrm{PA}_{46-54}$ in the prime boost setting. In contrast, only a minor response could be detected for the group that has received a single i.n. immu nization (Fig. 6A, lane 3). For both new vaccination protocols no antigen specific CTLs were detectable for the control groups immunized with adjuvant MS. Furthermore, a combination of a s.c. prime vaccination with $\mathrm{M} 1_{58-66} / \mathrm{CpG}$ MS and polyI:C MS and an i.n. boost vaccination with adjuvant MS just induced a negligible number of antigen specific CTLs (Fig. 6A, lane 11). A completely different picture could be observed in the lungs of the immunized mice (Fig. 6B). Here, the highest number of antigen specific CTLs was measured for M1 $1_{58-66} /$ CpG MS and polyI:C MS applied with the prime boost vaccination set ting (Fig. 6B, lane 5). In addition, $\mathrm{PA}_{46-54}$ and $\mathrm{M} 1_{58-66} / \mathrm{PA}_{46-54}$

A

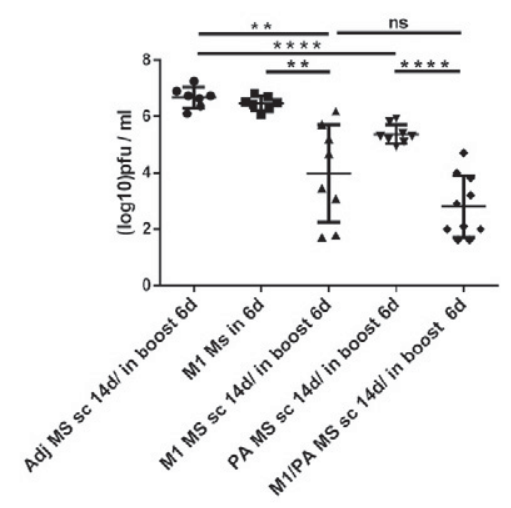

B
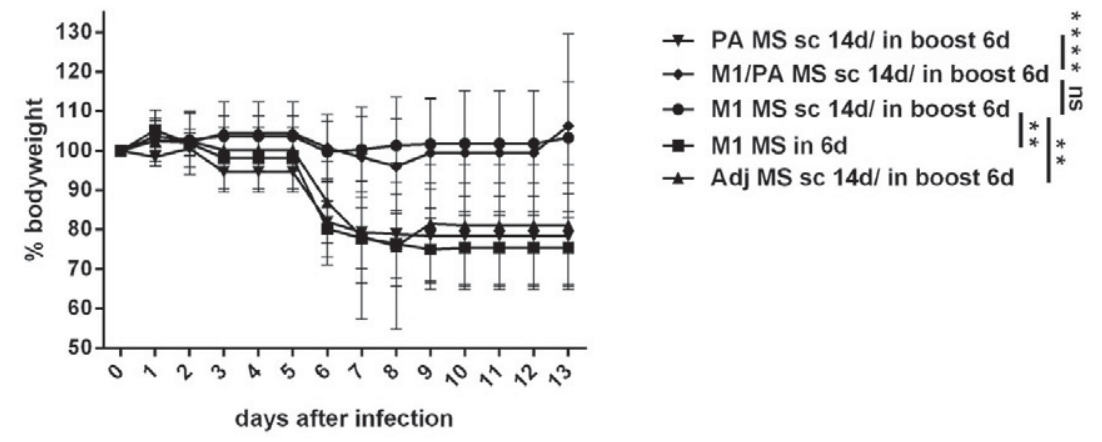

C

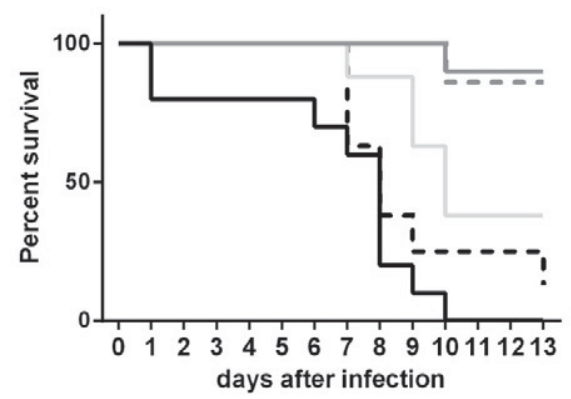

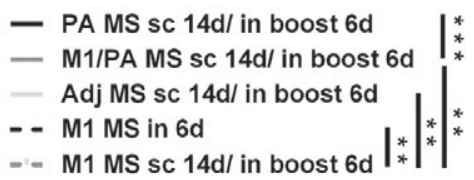

Fig. 7. Induction of influenza virus protective immunity by PLGA MS-based vaccination. For priming, AAD mice were s.c. immunized with 5 mg M1/CpG MS ( $\mathrm{m}=8$ ), PA/CpG MS or M1/PA/ CpG MS each combined with $5 \mathrm{mg}$ polyl:C MS. Mice of the control group were immunized with the corresponding amounts of CpG MS and polyl:C MS ( $\mathrm{n}=7$ ). Boost and single i.n. immunizations were performed with $2.5 \mathrm{mg}$ of the corresponding MS. Six days after vaccination, mice were challenged i.n. with $5 \times 10^{4}$ pfu RB1 H1N1pdm09 influenza virus. (A) $48 \mathrm{~h}$ after infection, lungs were taken for determination of the virus titer. Individual mice and the median values per group are shown. The $\mathrm{p}$ values were calculated by an unpaired t-test with Welsch's correction $\left({ }^{* *} \mathrm{p}=0.0028 ;{ }^{* *} \mathrm{p}=0.0045,{ }^{* * *} \mathrm{p} \leq 0.0001\right)$. Bodyweight (B) and survival (C) was monitored during a time period of 13 days after infection. Median values per group are shown. The $\mathrm{p}$ values were calculated by a paired t-test $\left((\mathrm{B}){ }^{* * * *} \mathrm{p}=0.0009 ;{ }^{* * * *} \mathrm{p}=0.0003 ;{ }^{* * * *} \mathrm{p}=<0.0001\right) ;\left((\mathrm{C}){ }^{*} \mathrm{p}=0.0401 ;{ }^{* *} \mathrm{p}=0.0089 ;{ }^{* *} \mathrm{p}=0.0040 ;{ }^{* * *} \mathrm{p}=0.0002\right)$. 
administered according to the prime boost vaccination setting could in duce a CTL response, too (Fig. 6B, lane 7). In contrast, there was only a low response after single s.c. or single i.n. vaccination with $\mathrm{M} 1_{58-66}$ MS (Fig. 6B, lanes 1 and 3) and no measurable response for the control groups. Interestingly, an s.c. antigen specific prime followed by an un specific, inflammatory stimulus in the lung also led to no CTL response in the lung (Fig. 6B, lane 11) thus indicating that a successful i.n. boost relies on antigen to accumulate specific CTLs in the lung. Encapsulation of the two peptides into different MS with one TLR ligand each resulted in a slightly higher response in the lung but not in the spleen (Fig. 6B, lanes $9+10$ ) compared to the M1/PA/CpG MS and polyl:C MS setting (Fig. 6B, lanes $7+8$ ). In addition, i.n. prime and i.n. boost with M1 MS (Fig. 6B, lane 12) were not as potent as i.n. boost after s.c. prime.

\subsection{Heterologous vaccination with PLGA MS leads to protective immunity against influenza virus infection}

Next, we wanted to investigate if the systemic and mucosal immunity induced by the heterologous prime boost vaccination scheme enables protection against challenge with a lethal dose of influenza virus. Single i.n. immunization with $\mathrm{M}_{58-66} / \mathrm{CpG} \mathrm{MS}$ and polyI:C displayed no protec tive capacity against pandemic influenza virus H1N1pdm09 (Fig. 7A). High virus titers measured $48 \mathrm{~h}$ after infection in the lung correlated with a tremendous weight loss of both groups between days five and six and subsequent infection related death (Fig. 7B/C). Mice that received a prime boost immunization with $\mathrm{PA}_{46-54} / \mathrm{CpG}$ MS and polyI:C MS showed significantly reduced virus titers compared to the mice immu nized with the adjuvants MS, but were not protected against infection related weight loss and morbidity. Both, mice vaccinated with $\mathrm{M} 1_{58-66}$ and $\mathrm{PA}_{46-54}$ and $\mathrm{CpG}$ co encapsulated into one microsphere mixed with polyl:C MS and mice vaccinated with $M 1_{58-66} / \mathrm{CpG}$ MS and polyI:C MS according to the prime boost setting not only showed both systemic and vigorous CTL responses in the lung (Fig. $6 \mathrm{~B}$ ) but were also protected from influenza virus infection (Fig. 7B/C). In accordance with a signifi cantly reduced virus titer in the lung, no weight loss was observable. In summary, vaccination with the conserved and well defined epitopes $\mathrm{M}_{58-66}$ and $\mathrm{PA}_{46-54}$ co encapsulated together with the TLR9 ligand CPG ODN into clinically compatible PLGA microspheres and mixed with microspheres encapsulating the TLR3 ligand polyl:C enable control of influenza A virus infections.

\subsection{Heterologous vaccination induces sustained immune responses}

Immunity against influenza virus should ideally last for at least one influenza season. After vaccination according to our heterologous vacci nation scheme, immune responses were detectable both in spleen and lung for four weeks. Moreover, specific CTLs in lung and spleen could be restimulated with an additional intranasal boost immunization after decay of the initial immune response (Fig. 8A/B). In the spleen, the number of specific CTLs more than doubled between weeks one and two after the boost immunization, probably due to migration from the lung to the spleen. Between weeks two and four the number of CTLs in the lung remained stable until a strong decrease in week eight (Fig. 8A). In the lung, equal numbers of specific CTLs were observable during the first three weeks. After eight weeks, no specific CTLs were measurable in the lung anymore (Fig. 8B). Re boost after eight weeks induced robust CTL responses both in the lung and spleen indicating an efficient formation of T memory cells.

\section{Discussion}

The most pivotal task in the fight against a recurrence of an influ enza virus pandemic is the development of a vaccine that induces heterosubtypic protection against all influenza A viruses. Heterosubtypic immunity is mediated by serotype cross reactive CTLs specific for conserved internal proteins like the matrix protein $[13,27]$. Induction of CTL responses in contrast to an antibody response is indispensable for the suppression of initial viral replication in the respiratory epithelium [12] and furthermore can provide partial $[28,29]$ or complete protection of mice from heterosubtypic influenza viruses [30,31]. CTLs induce apoptosis of virus infected cells after recognizing viral peptides bound to major histocompatibility complex (MHC) class I molecules and secrete antiviral cytokines, notably interferon $\gamma$ and tumor necrosis factor [32]. Following natural influenza A virus infection the CTL response of HLA A* $0201^{+}$individuals (i.e., approx. $50 \%$ of the Caucasian population) is exquisitely focused on the immunodominant $\mathrm{M} 1_{58-66}$ peptide [33,34].

In our study, we investigated the potency of PLGA MS based vacci nation with M1 $1_{58-66}$ peptide. We could show that PLGA MS containing $M 1_{58-66}$ peptide and the TLR ligand $\mathrm{CpG}$ mixed with polyI:C MS were capable of inducing robust CTL responses in HLA A*0201 transgenic mice after a single subcutaneous vaccination without the need to induce antigen specific $\mathrm{T}$ helper cells. Peptide vaccines provide several
A

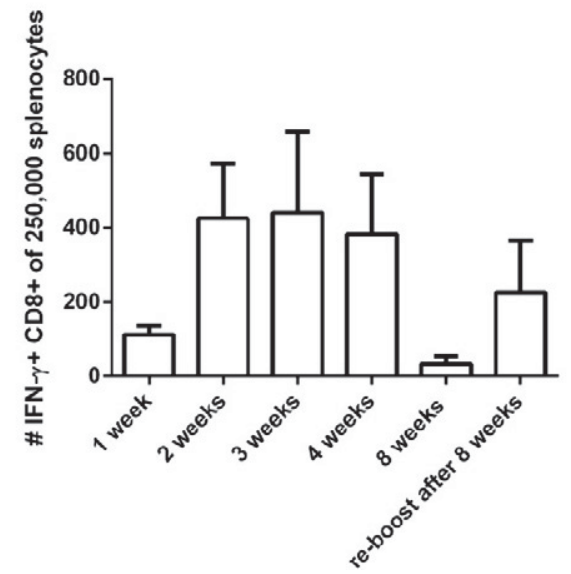

B

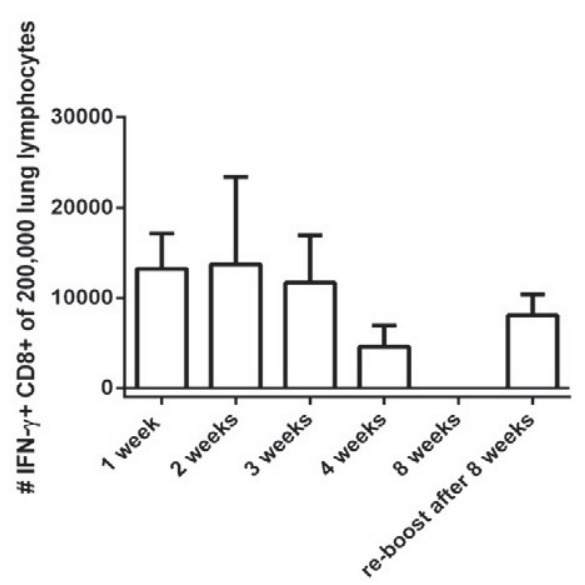

Fig. 8. Subcutaneous priming and intranasal boosting with PLGA-MS induces sustained immune responses in spleen and lung. (A/B) For priming, AAD mice were s.c. immunized with M1/ CpG MS ( $\mathrm{n}=3$ ) MS and polyI:C MS. Boost and re-boost i.n. immunizations were performed with $2.5 \mathrm{mg}$ M1/CpG MS. 1, 2, 3, 4 and 8 weeks after the boost immunization, and 6 days after the re-boost (week 9) splenocytes (A) and lung cells (B) were isolated and analyzed for IFN- $\gamma$ production after peptide restimulation by ICS. Background levels (no peptide) were subtracted. Values (mean \pm SEM) are given in (A) as absolute numbers of IFN- $\gamma^{+}$CD8 $8^{+}$lymphocytes per $2.5 \times 10^{5}$ counted splenocytes and in (B) as absolute numbers of IFN- $\gamma^{+}$ $\mathrm{CD}^{+}$cells per $2 \times 10^{5}$ lung leukocytes. 
advantages over the currently used inactivated viral vaccines. Peptides can be easily produced in large scale and bear no risk of infectious particles. In addition, PLGA MS protect the encapsulated peptides from proteolytic degradation, thus a lower antigen dose is required. Further more, the use of PLGA MS as an antigen delivery device provides a depot effect and therefore a prolonged antigen release [19,35]. This leads to a CTL response that peaks on day 6 and reaches even beyond day 35 after immunization (Fig. 2C). The promptitude of the CTL response is of special interest, as early viral clearance after influence A virus infection is required for both, significant reduction in the severity of symptoms and the prevention of lethal viral pneumonia [36,37]. Direct pulsing of DCs with MHC class I restricted influenza virus epitopes without usage of a vaccine delivery system was reported to induce potent antiviral CTL responses though leading to a delayed clearance of an influenza virus challenge [38]. An advantage of peptide vaccines is the fact that they are flexible in their design and can therefore contain more than one antigen, which increases the clonality of the elicited $\mathrm{T}$ cell response [14]. As immune escape by antigenic drift is a threat to the potency of a vaccination against influenza virus, it is advantageous to use such a multi epitope vaccine. The only limitation however is the number of different peptides that can be encapsulated into one microsphere. Co encapsulation of the influenza epitopes $\mathrm{M}_{58-66}$ and $\mathrm{PA}_{46-54}$ though led to an equally strong CTL response as single encapsulation of each peptide (Fig. 3C). Being dependent on CTL activity, protection against vaccinia virus is a good model for viral infection. In fact, we were not only able to show an effective CTL induction by measuring the IFN $\gamma$ release of antigen specific $\mathrm{CD} 8^{+}$splenocytes but we could also evidence their functionality in viral protection after systemic vaccination with PLGA MS bearing the viral epitope $\mathrm{M} 1_{58-66}$. However, systemic immuni zation with M1 $1_{58-66}$ containing PLGA MS did neither ease the symptoms nor lead to an extended survival after infection with influenza A virus.

It was previously reported that systemic administration of vaccines generally fails to induce mucosal immunity while mucosal immuniza tions have the ability to induce both local and systemic immunity and therefore induce local long term immunological memory at the site of entry [39]. In addition, s.c. immunization does not lead to an instant elimination of the infected airway epithelial cells by the induced CTLs even though i.v. injected target cells are destroyed rapidly [11]. However, intranasal administration of $\mathrm{M}_{58-66}$ microspheres neither induced specific CTLs in the spleen nor in the lung of the immunized mice. Wells et al., in contrast, already demonstrated that transferred lympho cytes from previously infected mice migrated to the lungs of the host mice during influenza virus infection and led to an earlier and greater reduction in pulmonary virus titer. On the other hand, transfer of naive lymphocytes to infected mice resulted in a very late reduction of the pulmonary virus titer on day 21 [36]. Additionally, a systemic prime was needed prior to mucosal immunization with microparticles containing simian immunodeficiency virus (SIV) to induce protective immunity in macaques challenged with SIV [40].

A systemic prime vaccination could also contribute to the establishment of long term memory as it was shown before that the memory $\mathrm{T}$ cell population in the lung airways is dynamic and depends on a systemic source of $\mathrm{T}$ cells that is continually recruited from the circulation. This implicates a significant connection of memory $\mathrm{T}$ cell pools in the secondary lymphoid organs and those in peripheral tissues [41]. In fact, systemic prime vaccination and intranasal boost vaccination resulted in a prominent CTL infiltration of the lung including a significantly higher number of $\mathrm{M} 1_{58-66}$ specific CTLs (Fig. 6B). Vaccina tion with the two well defined and conserved virus epitopes M1 $1_{58-66}$ and $\mathrm{PA}_{46-54}$ encapsulated into clinically compatible PLGA microspheres contributed to the control of influenza A virus infections and interferes with virus replication, weight loss, and infection related death (Fig. 7). As intranasal vaccination does not require injection it is less painful and has therefore a high patient compliance. Application would also not require trained medical personnel, which is a great benefit in mass vaccination programs or in countries with poor health care. Interestingly, neither a single intranasal immunization nor a single subcutaneous vaccination was sufficient to induce a robust CTL response in the lung (Fig. 6B). These results indicate that both, mucosal and systemic immu nity are needed to induce protective immunity in the lung. Single s.c. immunization might not be sufficient, because injected vaccines are generally poor inducers of mucosal immunity. Single i.n. vaccination alone on the other hand could induce tolerance as mucosal surfaces are adapted to the presence of foreign microorganisms. In addition, an inflammatory stimulus in terms of an adjuvant boost after a peptide spe cific prime vaccination also does not lead to a cross protective immunity through migration of antigen specific cells from the lymphoid organs to the lung mucosa. Ninomiya et al. even stated that both MHC class I and class II are necessary after vaccination with a MHC class I restricted influenza virus epitope encapsulated in liposomes and anti CD40 $\mathrm{mAb}$ to induce protective immunity against influenza $\mathrm{A}$ virus in mice [16]. However, protection against influenza A virus infection through humoral and cell mediated immunity was also reported after s.c. or i.p. immunization of mice with HA split product virus vaccines encap sulated into poly(gamma glutamic acid) graft L phenylalanine nano particles [42].

The usage of $\mathrm{CpG}$ ODN and polyI:C as adjuvants activates innate signaling pathways and helps the vaccine to be distinguished from commensal bacteria. Furthermore, these two TLR ligands generate a strong Th1 polarizing condition, minimizing the probability of unwanted tolerance induction. PLGA MS themselves also help to circumvent toler ance as they are specifically taken up by professional antigen presenting cells. A study by Maroof et al. showed, that intranasal vaccination with a TLR4 agonist and a detergent split influenza antigen promotes antigen specific antibody responses but also polyfunctional antigen specific Th17 cells leading to increased weight loss and morbidity during the early stages of disease [43]. The utilization of CpG ODN and polyI: $\mathrm{C}$ in our vaccination protocol, in contrast, generates a strong Th1 polarizing condition, which in combination with the usage of a peptide exclusively presented on HLA A* 0201 to $\mathrm{CD}^{+}{ }^{+}$cytotoxic T cells, limits the danger of the induction of an unwanted Th17 cell mediated, vaccine induced IL 17 response. Consistent with this, no increased weight loss or morbidity was observable for our vaccination. Similarly, Ichihashi et al. already could demonstrate that immunization of HLA A*2420 transgenic mice with liposome conjugated HLA A*2420 restricted influenza virus peptides in the presence of $\mathrm{CpG}$ ODN protected from lethal influenza virus challenge. In contrast to our study, a single peptide was not able to mediate this effect, but three epitopes were necessary to induce protection [11].

\section{Conclusions}

In conclusion, we have established a safe and powerful vaccination against influenza virus infection that interferes with virus replication, weight loss and infection related death in a mouse model, which very closely reflects the human situation. This applicable approach could help to foreclose pandemic outbreaks of influenza viruses, especially in countries with high HLA $A^{*} 0201$ allele frequencies like Europe as well as North and South America.

\section{Acknowledgments}

We thank Vivien Weber for the help with virus titer determina tions, the personnel of the animal research facility of Konstanz Uni versity for the professional animal care taking, and Stefanie Buerger of the flow cytometry facility FlowKon for the support. We acknowledge Bruno Gander and Manfred Kopf for valuable advice. V.H. is a member of the DFG Research Training Group 1331. This work was supported by the German Research Foundation (DFG) (GR 1517). 


\section{References}

[1] WHO, Influenza fact sheet no. 211Available from: www.whoint/mediacentre/ factsheets/fs211/en/ 2014.

[2] J.C. de Jong, A.M. Palache, W.E. Beyer, G.F. Rimmelzwaan, A.C. Boon, A.D. Osterhaus, Haemagglutination-inhibiting antibody to influenza virus, Dev. Biol. 115 (2003) 63-73.

[3] B. Olsen, V.J. Munster, A. Wallensten, J. Waldenstrom, A.D. Osterhaus, R.A. Fouchier, Global patterns of influenza a virus in wild birds, Science 312 (2006) 384-388.

[4] T.K. Berthoud, M. Hamill, P.J. Lillie, L. Hwenda, K.A. Collins, K.J. Ewer, A. Milicic, H.C. Poyntz, T. Lambe, H.A. Fletcher, A.V. Hill, S.C. Gilbert, Potent CD8 + T-cell immunogenicity in humans of a novel heterosubtypic influenza A vaccine, MVA-NP+M1, Clin. Infect. Dis. 52 (2011) 1-7.

[5] K.M. Grebe, J.W. Yewdell, J.R. Bennink, Heterosubtypic immunity to influenza A virus: where do we stand? Microbes Infect. 10 (2008) 1024-1029.

[6] N. Arinaminpathy, O. Ratmann, K. Koelle, S.L. Epstein, G.E. Price, C. Viboud, M.A. Miller, B.T. Grenfell, Impact of cross-protective vaccines on epidemiological and evolutionary dynamics of influenza, Proc. Natl. Acad. Sci. U. S. A. 109 (2012) 3173-3177.

[7] A. Takada, S. Matsushita, A. Ninomiya, Y. Kawaoka, H. Kida, Intranasal immunization with formalin-inactivated virus vaccine induces a broad spectrum of heterosubtypic immunity against influenza A virus infection in mice, Vaccine 21 (2003) 3212-3218.

[8] A.J. McMichael, F.M. Gotch, G.R. Noble, P.A. Beare, Cytotoxic T-cell immunity to influenza, N. Engl. J. Med. 309 (1983) 13-17.

[9] F. Gotch, A. McMichael, G. Smith, B. Moss, Identification of viral molecules recognized by influenza-specific human cytotoxic T lymphocytes, J. Exp. Med. 165 (1987) 408-416.

[10] H.J. Zweerink, S.A. Courtneidge, J.J. Skehel, M.J. Crumpton, B.A. Askonas, Cytotoxic T cells kill influenza virus infected cells but do not distinguish between serologically distinct type A viruses, Nature 267 (1977) 354-356.

[11] T. Ichihashi, R. Yoshida, C. Sugimoto, A. Takada, K. Kajino, Cross-protective peptide vaccine against influenza $A$ viruses developed in HLA-A*2402 human immunity model, PLoS One 6 (2011) e24626.

[12] A. Takada, H. Kida, Protective immune response of chickens against Newcastle disease, induced by the intranasal vaccination with inactivated virus, Vet. Microbiol. 50 (1996) 17-25.

[13] H.H. Nguyen, Z. Moldoveanu, M.J. Novak, F.W. van Ginkel, E. Ban, H. Kiyono, J.R. McGhee, J. Mestecky, Heterosubtypic immunity to lethal influenza A virus infection is associated with virus-specific CD8 $(+)$ cytotoxic T lymphocyte responses induced in mucosa-associated tissues, Virology 254 (1999) 50-60.

[14] J.D. Comber, R. Philip, MHC class I antigen presentation and implications for developing a new generation of therapeutic vaccines, Ther. Adv. Vaccines 2 (2014) 77-89.

[15] A.W. Purcell, J. McCluskey, J. Rossjohn, More than one reason to rethink the use of peptides in vaccine design, Nat. Rev. Drug Discov. 6 (2007) 404-414.

[16] A. Ninomiya, K. Ogasawara, K. Kajino, A. Takada, H. Kida, Intranasal administration of a synthetic peptide vaccine encapsulated in liposome together with an anti-CD40 antibody induces protective immunity against influenza A virus in mice, Vaccine 20 (2002) 3123-3129.

[17] P. Johansen, Y. Men, H.P. Merkle, B. Gander, Revisiting PLA/PLGA microspheres: an analysis of their potential in parenteral vaccination, Eur. J. Pharm. Biopharm. 50 (2000) 129-146.

[18] Y. Waeckerle-Men, E. Uetz von Allmen, R. von Moos, B.J. Classon, E. Scandella, H.P. Schmid, B. Ludewig, M. Groettrup, S. Gillessen, Dendritic cells generated from androgen-independent prostate carcinoma patients are not impaired in migration and T cell stimulation, Prostate 64 (2005) 323-331.

[19] R. Audran, K. Peter, J. Dannull, Y. Men, M. Groettrup, B. Gander, G. Corradin, Encapsulation of peptides prolongs their presentation to cytotoxic T cells by antigen presenting cells in vitro, Vaccine 21 (2003) 1250-1255.

[20] K.D. Newman, P. Elamanchili, G.S. Kwon, J. Samuel, Uptake of poly(D,L-lactic-coglycolic acid) microspheres by antigen-presenting cells in vivo, J. Biomed. Mater. Res. 60 (2002) 480-486.

[21] Y. Waeckerle-Men, E. Uetz-von Allmen, M. Fopp, R. von Moos, C. Boehme, H.P. Schmid, D. Ackermann, T. Cerny, B. Ludewig, M. Groettrup, S. Gillessen, Dendritic cell-based multi-epitope immunotherapy of hormone-refractory prostate carcinoma, Cancer Immunol. Immunother. 55 (2006) 1524-1533.

[22] E. Schlosser, M. Mueller, S. Fischer, S. Basta, D.H. Busch, B. Gander, M. Groettrup, TLR ligands and antigen need to be coencapsulated into the same biodegradable microsphere for the generation of potent cytotoxic T lymphocyte responses, Vaccine 26 (2008) 1626-1637.

[23] Y. Waeckerle-Men, B. Gander, M. Groettrup, Delivery of tumor antigens to dendritic cells using biodegradable microspheres, Methods Mol. Med. 109 (2005) 35-46.

[24] E. Haasbach, C. Hartmayer, A. Hettler, A. Sarnecka, U. Wulle, C. Ehrhardt, S. Ludwig, O. Planz, Antiviral activity of Ladania067, an extract from wild black currant leaves against influenza A virus in vitro and in vivo, Front. Microbiol. 5 (2014) 171.

[25] C. Gianfrani, C. Oseroff, J. Sidney, R.W. Chesnut, A. Sette, Human memory CTL response specific for influenza A virus is broad and multispecific, Hum. Immunol. 61 (2000) 438-452.

[26] C.K. Li, R. Rappuoli, X.N. Xu, Correlates of protection against influenza infection in humans-on the path to a universal vaccine? Curr. Opin. Immunol. 25 (2013) 470-476.

[27] F. Gotch, J. Rothbard, K. Howland, A. Townsend, A. McMichael, Cytotoxic T lymphocytes recognize a fragment of influenza virus matrix protein in association with HLA-A2, Nature 326 (1987) 881-882.

[28] K. Okuda, A. Ihata, S. Watabe, E. Okada, T. Yamakawa, K. Hamajima, J. Yang, N. Ishii, M. Nakazawa, K. Okuda, K. Ohnari, K. Nakajima, K.Q. Xin, Protective immunity against influenza A virus induced by immunization with DNA plasmid containing influenza M gene, Vaccine 19 (2001) 3681-3691.

[29] S. Roy, G.P. Kobinger, J. Lin, J. Figueredo, R. Calcedo, D. Kobasa, J.M. Wilson, Partial protection against H5N1 influenza in mice with a single dose of a chimpanzee adenovirus vector expressing nucleoprotein, Vaccine 25 (2007) 6845-6851.

[30] S.L. Epstein, W.P. Kong J.A. Misplon, C.Y. Lo, T.M. Tumpey, L. Xu, G.J. Nabel, Protection against multiple influenza A subtypes by vaccination with highly conserved nucleoprotein, Vaccine 23 (2005) 5404-5410.

[31] M. Matsui, S. Kohyama, T. Suda, S. Yokoyama, M. Mori, A. Kobayashi, M. Taneichi, T. Uchida, A CTL-based liposomal vaccine capable of inducing protection against heterosubtypic influenza viruses in HLA-A*0201 transgenic mice, Biochem. Biophys. Res. Commun. 391 (2010) 1494-1499.

[32] P.G. Thomas, R. Keating, D.J. Hulse-Post, P.C. Doherty, Cell-mediated protection in influenza infection, Emerg. Infect. Dis. 12 (2006) 48-54.

[33] M.A. Bednarek, S.Y. Sauma, M.C. Gammon, G. Porter, S. Tamhankar, A.R. Williamson, H.J. Zweerink, The minimum peptide epitope from the influenza virus matrix protein, J. Immunol. 147 (1991) 4047-4053.

[34] J. Morrison, J. Elvin, F. Latron, F. Gotch, R. Moots, J.L. Strominger, A. McMichael, Identification of the nonamer peptide from influenza A matrix protein and the role of pockets of HLA-A2 in its recognition by cytotoxic T lymphocytes, Eur. J. Immunol. 22 (1992) 903-907.

[35] Y. WaeckerleMen, E. UetzvonAllmen, B. Gander, E. Scandella, E. Schlosser, G. Schmidtke, H.R. Merkle, M. Groettrup, Encapsulation of proteins and peptides into biodegradable poly(D,L-lactide-co-glycolide) microspheres prolongs and enhances antigen presentation by human dendritic cells, Vaccine 24 (2006) 1847-1857.

[36] M.A. Wells, F.A. Ennis, P. Albrecht, Recovery from a viral respiratory infection. II. Passive transfer of immune spleen cells to mice with influenza pneumonia, J. Immunol. 126 (1981) 1042-1046.

[37] K.L. Yap, G.L. Ada, I.F. McKenzie, Transfer of specific cytotoxic T lymphocytes protects mice inoculated with influenza virus, Nature 273 (1978) 238-239.

[38] S.R. Crowe, S.C. Miller, R.M. Shenyo, D.L. Woodland, Vaccination with an acidic polymerase epitope of influenza virus elicits a potent antiviral T cell response but delayed clearance of an influenza virus challenge, J. Immunol. 174 (2005) 696-701.

[39] M. Vajdy, D.T. O'Hagan, Microparticles for intranasal immunization, Adv. Drug Deliv. Rev. 51 (2001) 127-141.

[40] P.A. Marx, R.W. Compans, A. Gettie, J.K. Staas, R.M. Gilley, M.J. Mulligan, G.V. Yamshchikov, D. Chen, J.H. Eldridge, Protection against vaginal SIV transmission with microencapsulated vaccine, Science 260 (1993) 1323-1327.

[41] K.H. Ely, T. Cookenham, A.D. Roberts, D.L. Woodland, Memory T cell populations in the lung airways are maintained by continual recruitment, J. Immunol. 176 (2006) 537-543.

[42] S. Okamoto, H. Yoshii, T. Akagi, M. Akashi, T. Ishikawa, Y. Okuno, M. Takahashi, K. Yamanishi, Y. Mori, Influenza hemagglutinin vaccine with poly(gamma-glutamic acid) nanoparticles enhances the protection against influenza virus infection through both humoral and cell-mediated immunity, Vaccine 25 (2007) 8270-8278.

[43] A. Maroof, Y.M. Yorgensen, Y. Li, J.T. Evans, Intranasal vaccination promotes detrimental Th17-mediated immunity against influenza infection, PLoS Pathog. 10 2014) e1003875. 